\title{
PENERAPAN TAX PLANNING SEBAGAI ALTERNATIF MEMINIMALKAN PAJAK UNTUK MENGOPTIMALKAN LABA PERUSAHAAN PADA CV. LINBO
}

\author{
Nining Asniar Ridzal \\ Program Studi Akuntansi, Fakultas Ekonomi \\ Universitas Muhammadiyah Buton, Baubau, Indonesia \\ e-mail :nining.asniar@umbuton.ac.id
}

\begin{abstract}
ABSTRAK
Tujuan dalam penelitian ini adalah untuk mengetahui penerapan tax planning sebagai alternatif meminimalkan pajak untuk mengoptimalkan laba perusahaan pada CV. Linbo. Metode analisis yang digunakan dalam penelitian ini adalah metode penelitian deskriptif yaitu suatu metode penelitian yang bertujuan memberikan gambaran keadaan yang sebenarnya dari objek yang diteliti berdasarkan faktafakta yang ada, dengan cara mengumpulkan, mengolah, dan menganalisis berbagai macam data sehingga dapat ditarik suatu kesimpulan.

Hasil penelitian menunjukkan bahwa berdasarkan Peraturan Pemerintah No. 46 Tahun 2013 tentang pajak penghasilan atas penghasilan dari usaha yang diterima atau diperoleh wajib pajak yang memiliki peredaran bruto tertentu., maka CV. Linbo dikenakan tarif pajak final sebasar $1 \%$ dari peredaran bruto. Sehubungan dengan pengenaan tarif final $1 \%$ makaCV. Linbo tidak bisa menerapkan tax planningkarena tax planning hanya bisa diterapkan oleh perusahaan yang peredaran brutonya di atas Rp. 4,8 milyar atau perusahaan yang tidak dikenakan pajak final $1 \%$.
\end{abstract}

KataKunci :Tax Planning, Pajak Penghasilan, Laba Optimal

\section{ABSTRACT}

The purpose of this research is to find out the application of tax planning as an alternative to minimize tax to optimize company profits on CV. Linbo. The analytical method used in this study is descriptive research method, which is a research method that aims to provide an overview of the actual state of the object under study based on the facts, by collecting, processing, and analyzing various types of data so that conclusions can be drawn.

The results showed that based on Government Regulation No. 46 of 2013 concerning income tax on income from business received or obtained by taxpayers who have certain gross circulation, thus $C V$. Linbo is subject to a final tax rate of $1 \%$ of gross circulation. In connection with the imposition of a final rate of $1 \%, C V$. Linbo cannot implement tax planning because tax planning can only be applied by companies whose gross circulation is above Rp. 4.8 billion or companies not subject to final tax of $1 \%$.

Keywords: Tax Planning, Income Tax, Optimal Profit 


\section{PENDAHULUAN}

Salah satu kewajiban kewarganegaraan setiap orang adalah membayar pajak sesuai ketentuan undang-undang.Sebagai salah satu sumber penerimaan negara, pajak memiliki peran yang sangat besar dan semakin diandalkan untuk kepentingan pembangunan dan pengeluaran pemerintahan [1].Sedangkan masalah serius yang dimiliki oleh warga negara adalah membayar pajak yang tidak sedikit. Oleh karena itu untuk meminimalisasikan beban pajak, manajer perusahaan dapat menggunakan salah satu cara di dalam perpajakan yang dikenal dengan manajemen pajak yaitu upaya memenuhi kewajiban perpajakan dengan benar melalui perencanaan, pengorganisasian, pengarahan, pengkoordinasian dan pengawasan mengenai perpajakan, sehingga beban pajak yang harus ditanggung oleh perusahaan dapat diminimalkan guna memperoleh laba yang diharapkan tanpa melanggar undang-undang yang berlaku [2].

Upaya untuk menekan pajak (yang terhutang lebih kecil dari yang seharusnya) membutuhkan suatu langkah-langkah manajemen yang terintegratif.Langkah-langkah manajemenyang dimaksud dimulai dari perencanaan hingga pengawasan terhadap program pengurangan pajak yang harus dilunasi oleh perusahaan [3].Pajak yang terhutang ditentukan dari penghasilan kena pajak (taxable income) yang dikalikan dengan tarif pajak [4]. Semakin besar Penghasilan Kena Pajak (PKP) maka makin besar pula pajak yang harus ditanggung, makin besar biaya yang dikeluarkan maka PKP akan semakin kecil sehingga pajak yang dibayar juga kecil.

Secara umum ketentuan perpajakan maupun peraturan-peraturannya yang tercantum dan diterbitkan dalam undang-undang atau peraturan-peraturan perpajakan lainnya yang sangat berpengaruh terhadap dunia usaha, hal tersebut akan meningkatkan kompetisi dan prestasi suatu badan usaha, dimana kegiatan usaha dilakukan untuk mencapai tujuan perusahaan, yaitu untuk mendapatkan laba yang sebesar-besarnya dan meminimalisasikan beban pajak yang ditanggung oleh perusahaan [5].Untuk meminimalisasikan beban pajak yang ditanggung wajib pajak dapat ditempuh dengan cara rekayasa yang masih berada dalam ruang lingkup perpajakan hingga di luar ketentuan perpajakan [6]. Upaya untuk meminimalisasi pajak sering disebut dengan teknik tax planning[7].

Perencanaan pajak (tax planning) mengacu kepada proses merekayasa usaha dan transaksi wajib pajak agar utang pajak berada dalam jumlah yang minimal, tetapi masih dalam bingkai peraturan perpajakan [8]Suandy (2008:6). Namun demikian, perencanaan pajak juga dapat diartikan sebagai perencanaan pemenuhan kewajiban perpajakan secara 
lengkap, benar, dan tepat waktu sehingga dapat secara optimal menghindari pemborosan sumber daya.

Tax planning merupakan langkah awal dalam manajemen pajak.Manajemen pajak itu sendiri merupakan sarana untuk memenuhi kewajiban perpajakan dengan benar, tetapi jumlah pajak yang dibayarkan dapat ditekan seminimal mungkin untuk memperoleh laba yang diharapkan.Langkah selanjutnya adalah pelaksanaan kewajiban perpajakan (tax implementation) dan pengendalian pajak (tax control).Pada tahap perencanaan pajak ini, dilakukan pengumpulan dan penelitian terhadap peraturan perpajakan seperti UU No. 36 Tahun 2008 [8]. Tujuannya adalah agar dapat dipilih jenis tindakan penghematan pajak yang akan dilakukan.

Upaya-upaya yang dapat dilakukan dalam melakukan tax planning dalam meminimalkan jumlah Pajak Penghasilan $(\mathrm{PPh})$ terutang badan, yaitu dengan memaksimalkan penghasilan yang dikecualikan, memaksimalkan biaya fiskal, meminimalkan biaya yang tidak diperkenankan sebagai pengurang serta pemilihan metode akuntansi [8].

$\mathrm{CV}$. Linbo merupakan perusahaan yang berorientasi mencari laba. Besarnya pengeluaran perusahaan akan mengurangi laba yang dihasilkan. Salah satu pengeluaran perusahaan yang berpengaruh terhadap laba bersih adalah beban pajak penghasilan yang harus ditanggung perusahaan.Untuk dapat meminimalkan pembayaran pajak dan mengoptimalkan laba perusahaan, manajemen dapat melakukan berbagai upaya termasuk meneliti kembali beban pajak yang seharusnya dibayar dan membuat tax planning atas pembayaran pajaknya. Dengan demikian diharapkan tax planning dapat menjadi salah satu upaya untuk meminimalkan pembayaran pajak perusahaan yang akan berpengaruh terhadap laba bersih yang diperoleh perusahaan. Penelitian ini berfokus pada penerapan tax planning sebagai alternatif meminimalkan pajak untuk mengoptimalkan laba perusahaan padaCV. Linbo.

\section{METODE PENELITIAN}

Jenis data terbagi atas dua yaitu data kuantitatif dan data kualitatif [9].Data kuantitatif adalah data yang berbentuk angka atau data kualitatif yang diangkakan, sedangkan data kualitatif adalah data yang dinyatakan dalam bentuk kata dan kalimat. Adapun jenis data yang akan digunakan dalam penelitian ini adalah:

1. Data kuantitatif yaitu data berupa angka-angka dari laporan keuangan CV. Linbo.

2. Data kualitatif yaitu data-data yang diperoleh dari CV. Linbo berupa sejarah berdirinya, struktur organisasi, serta tugas dan tanggung jawab karyawan. 
Sumber data dibedakan menjadi dua yaitu data primer dan data sekunder [10].Data primer adalah sumber data penelitian yang diperoleh secara langsung dari sumber asli, sedangkan data sekunder adalah sumber data yang diperoleh secara tidak langsung melalui media perantara.Data primerdalam penelitian ini yaitu data yang diperoleh dengan mengadakan wawancara langsung dengan karyawan dan manajer CV. Linbo.Sedangkan data sekunderyaitu data yang diperoleh melalui kepustakaan atau sumber-sumber tertulis seperti laporan keuangan CV. Linbo dan hasil penelitian yang relevan dengan penelitian ini.

Populasi adalah wilayah generalisasi yang terdiri atas obyek/subyek yang mempunyai kuantitas dan karakteristik tertentu yang ditetapkan oleh peneliti untuk dipelajari dan kemudian ditarik kesimpulannya [9].Populasi dalam penelitian ini adalah laporan keuangan CV. Linbo.Sampel adalah sebagian atau wakil populasi yang diteliti. Jika kita hanya akan meneliti sebagian dari populasi, maka penelitian tersebut disebut penelitian sampel [11]. Adapun sampel dalam penelitian ini adalah laporan laba-rugi CV. Linbo tahun 2013-2015.

Adapun metode pengumpulan data yang digunakan dalam penelitian ini antara lain metode kepustakaan, wawancara, dan dokumentasi.Metode kepustakaan dilaksanakan dengan mengumpulkan data dari buku-buku yang ada hubungannnya dengan penelitian yang diteliti.Metode wawancaraini digunakan untuk memperoleh data yang mendalam tentang laporan keuangan artinya bila data yang diperlukan belum terungkap melalui metode dokumentasi, maka hal ini dapat dinyatakan secara langsung kepada bagian pembukuan melalui wawancara.Metode dokumentasijuga dipergunakan untuk memperoleh dan mengumpulkan data mengenai sejarah singkat dan perkembangan usaha CV. Linbo.

Metode analisis data yang digunakan oleh penulis dalam penelitian ini adalah metode analisis deskriptif yaitu suatu metode penelitian yang bertujuan memberikan gambaran keadaan yang sebenarnya dari objek yang diteliti berdasarkan fakta-fakta yang ada, dengan cara mengumpulkan, mengolah, dan menganalisis berbagai macam data sehingga dapat ditarik suatu kesimpulan [13].

\section{HASIL DAN PEMBAHASAN}

\section{a. Hasil Penelitian}

Laporan keuangan yang disajikan oleh CV. Linbo telah sesuai dengan Standar Akuntansi Keuangan.Berikut ini adalah Laporan Laba/Rugi untuk tahun 2013-2015. 
Tabel 1.CV. Linbo

Laporan Laba/Rugi Komparasi sebelum Tax Planning

\begin{tabular}{|c|c|c|c|c|c|c|}
\hline AKUN & \multicolumn{2}{|c|}{2013} & \multicolumn{2}{|c|}{2014} & \multicolumn{2}{|c|}{2015} \\
\hline Pendapatan & & 350.000 .000 & & 450.000 .000 & & 482.000 .000 \\
\hline Harga Pokok Penjualan & & 292.200 .000 & & $\underline{362.600 .000}$ & & $\underline{387.800 .000}$ \\
\hline Laba kotor & & 57.800 .000 & & 87.400 .000 & & 94.200 .000 \\
\hline Biaya Penjualan & 6.000 .000 & & 6.000 .000 & & 7.000 .000 & \\
\hline Biaya Administrasi dan Umum & 2.000 .000 & & 2.000 .000 & & 2.500 .000 & \\
\hline Jumlah Biaya & & $(8.000 .000)$ & & $(8.000 .000)$ & & $(9.500 .000)$ \\
\hline Laba Operasional & & 499.800 .000 & & 79.400 .000 & & 84.700 .000 \\
\hline Pendapatan Lain-lain & 4.600 .000 & & 4.200 .000 & & 5.400 .000 & \\
\hline Biaya Lain-lain & $(3.600 .000)$ & & $(3.700 .000)$ & & $(4.200 .000)$ & \\
\hline & & 1.000 .000 & & 500.000 & & 1.200 .000 \\
\hline & & 50.800 .000 & & 79.900 .000 & & 85.900 .000 \\
\hline
\end{tabular}

Sumber : CV. Linbo

Dari laporan laba rugi pada tabel di atas dapat dilihat bahwa peredaran bruto $\mathrm{CV}$. Linbo di bawah 4,8 milyar maka sesuai Peraturan Pemerintah No. 46 tahun 2013 tentang pajak penghasilan maka CV. Linbo dikenakan tarif final yaitu $1 \%$ dari peredaran bruto. Berikut ini perhitungan pajak terutang CV. Linbo dari tahun 2013 hingga tahun 2015.

- Peredaran bruto tahun 2013 adalah sebesar Rp.350.000.000

Tarif pajak penghasilan untuk tahun 2013

$$
1 \% \text { x Rp350.000.000 = Rp3.500.000 }
$$

Laba bersih setelah pajak

Rp.50.800.000-Rp.3.500.000= Rp.47.300.000

- Peredaran bruto tahun 2014 adalah sebesar Rp.450.000.000

Tarif pajak penghasilan untuk tahun 2014

$1 \%$ X $450.000 .000=\mathrm{Rp} 4.500 .000$

Laba bersih setelah pajak

Rp79.900.000-Rp4.500.000=Rp.75.400.000

- Peredaran bruto tahun 2015 adalah sebesar Rp.482.000.000

Tarif pajak penghasilan untuk tahun 2015

$1 \%$ X $482.000 .000=$ Rp. 4.820 .000

Laba bersih setelah pajak

Rp.85.900.000-Rp. $4.820 .000=$

Rp. 81.080.000

Dari perhitungan laba rugi di atas diketahui laba dan tarif pajak yang di kenakan pada CV. Linbo untuk tahun 2013-2015 yaitu 1\% dari peredaran bruto masing- masing Rp. 3.500.000 untuk tahun pajak 2013, Rp. 4.500.000 untuk tahun pajak 2014, dan Rp. 4.820.000 untuk tahun pajak 2015. 


\section{b. Pembahasan}

Laporan keuangan yang disusun oleh CV. Linbo, merupakan gambaran dari proses usaha baik mengenai perkembangan kemajuan perusahaan serta hambatan-hambatan yang dihadapi pada saat beroperasinya perusahaan. Data dan laporan tersebut nantinya akan digunakan pimpinan sebagai bahan pertimbangan evaluasi dalam mengambil langkah-langkah usaha selanjutnya yang mengarah pada perkembangan serta kemajuan perusahaan. Untuk pencapaian rencana tersebut maka dilakukan efisiensi PPh Badan dengan beberapa cara legal untuk memperkecil pajak dari suatu badan usaha untuk meminimalkan PPh terutang.

Dalam melaksanakan perencanaan pajak wajib pajak berupaya untuk meminimalkan pajak, salah satunya adalah memaksimalkan penghasilan yang dikecualikan.Usaha memaksimalkan penghasilan yang dikecualikan adalah usaha yang memaksimalkan penghasilan yang bukan objek pajak.Karena itu, perlu diketahui penghasilan yang dikenakan pajak final dan penghasilan yang bukan objek pajak.Menurut Undang-undang tentang pajak penghasilan, UU No. 36 Tahun 2008, penghasilan kena pajak adalah gross incomekurang biaya yang dikeluarkan untuk mendapatkan penghasilan kotor badan usaha.

Peraturan terbaru yang mengatur tentang tarif pajak penghasilan yaitu Peraturan Pemerintah No. 46 tahun 2013 tentang pajak penghasilan atas penghasilan dari usaha yang diterima atau diperoleh wajib pajak yang memiliki peredaran bruto tertentu. Dan jika melihat peredaran bruto CV. Linbo dari tahun 2013-2015 yaitu masing-masing Rp.350.000.000 untuk tahun 2013, Rp.450.000.000 untuk tahun 2014, dan Rp. 482.000.000 untutk tahun 2015 yang kurang dari Rp. 4,8 milyar maka pengenaan tarif pajaknya yaitu dikenakan tarif final sebasar $1 \%$ dari peredaran bruto.

Sehubungan dengan pengenaan tarif final $1 \%$ maka CV. Linbo tidak bisa menerapkan tax planningkarena tax planning hanya bisa diterapkan oleh perusahaan yang peredaran brutonya di atas Rp. 4,8 milyar atau perusahaan yang tidak dikenakan pajak final $1 \%$.

\section{KESIMPULAN}

Berdasarkan analisis data maka kesimpulan yang dapat diambil pada penelitian ini yaitu dilihat dari peredaran bruto CV. Linbo dari tahun 2013-2015 yang kurang dari Rp. 4,8 milyar maka pengenaan tarif pajaknya dikenakan tarif pajak final sebasar $1 \%$. Hal ini berdasarkan Peraturan Pemerintah No. 46 tahun 2013 tentang pajak penghasilan atas 
penghasilan dari usaha yang diterima atau diperoleh wajib pajak yang memiliki peredaran bruto tertentu. Sehubungan dengan pengenaan tarif final $1 \%$ maka CV. Linbo tidak bisa menerapkan tax planning karena tax planning hanya bisa diterapkan oleh perusahaan yang peredaran brutonya di atas Rp. 4,8 milyar atau perusahaan yang tidak dikenakan pajak final 1\%. Dengan demikian tax planning tidak berlaku pada CV. Linbo.

\section{SARAN}

Berdasarkan hasil penelitian yang dilakukan maka penulis memberikan saran yaitu diharapkan CV. Linbo selalu membayar pajaknya tepat waktu seperti selama ini agar terhindar dari denda dan sanksi perpajakan, serta mengikuti perkembangan peraturan perpajakan agar terhindar dari kesalahan.

\section{DAFTAR PUSTAKA}

[1] Supadmi, Ni Luh. 2009. Meningkatkan Kepatuhan Wajib Pajak Melalui Kualitas Pelayanan. Jurnal Akuntansi dan Bisnis, Volume 4, No. 2: 1 - 14.

[2] Rahman, Abdul. 2010. Perencanaan Pajak Perlukah? Kajian Praktis Menuju Administrasi Perpajakan yang Efisien.Jurnal Ilmu Administrasi, Volume 7, No. 2: 75 -85 .

[3] Anisa, R. Ridha dan Bertari D. H. 2015. Analisa Faktor yang Memotivasi Manajemen Perusahaan Melakukan Tax Planning.Accounting Analysis Journal, Volume 4, No. 1.

[4] Republik Indonesia. Undang-Undang No.16 Tahun 2009 Tentang Perubahan Keempat Atas Undang-Undang No.6 Tahun 1983 Tentang Kententuan Umum Dan Tata Cara Perpajakan (KUP).

[5] Mangusong, Soddin. 2002. Peranan Tax Planning dalam Mengefisienkan Pembayaran Pajak Penghasilam. Jurnal Ilmiah Akuntansi, Volume 2, No. 1.

[6] Zain, Muhammad. 2208. Manajemen Perpajakan Edisi 3. Jakarta: Salemba Empat.

[7] Rori, Handi. 2013. Analisis Penerapan Tax Planning atas Pajak Penghasilan Badan.Jurnal EMBA, Volume 1, No. 3: 410 - 418.

[8] Suandy, Erly. 2011. Perencanaan PajakEdisi 5. Jakarta: Salemba Empat.

[9] Sugiyono. 2013. Metode Penelitian Manajemen. Bandung: Alfabeta

[10] Indriantoro, Nur. 2002. Penelitian Bisnis Untuk Akuntansi dan Manajemen. Edisi 2. Yogyakarta: BPFE.

[11] Arikunto, Suharsimi. 2006. Prosedur Penelitian Suatu Pendekatan Praktek. Jakarta: Rineka Cipta.

[12] Nasir, M. 2003. Metode Penelitian. Jakarta: Ghalia Indonesia.

[13] Silalahi, Ulber. 2006. Metode Penelitian Sosial.Bandung: Unpar Press. 